\title{
Identifikasi Struktur Geologi Dasar Laut Sulawesi Berdasarkan Anomali Magnetik
}

Fila Alpiana ${ }^{\mathrm{a}}$, Catur Purwanto ${ }^{\mathrm{b}}$ Yudha Armana, Apriansyah ${ }^{\mathrm{c}}$

aProdi Geofisika, FMIPA Universitas Tanjungpura, Pontianak

bPusat Penelitian dan Pengembangan Geologi Kelautan, Bandung,

cProdi Kelautan, FMIPA Universitas Tanjungpura, Pontianak

*Email : filaalpiana@student.untan.ac.id

\begin{abstract}
Abstrak
Penelitian ini bertujuan untuk mengetahui struktur geologi di Laut Sulawesi dengan menggunakan metode magnetik. Data yang diperoleh dari hasil survei yaitu data intensitas medan magnet. Pengolahan data awal dilakukan koreksi harian dan koreksi IGRF (International Geomagnetic Reference Field) pada data hasil survei untuk mendapatkan anomali medan magnet total. Kemudian di reduksi ke kutub dan selanjutnya dilakukan pemisahan anomali lokal dan regional dengan filter gaussian regional/residual untuk mendapatkan anomali lokal. Didapatkan nilai anomali magnetik pada daerah penelitian -290,0 nT hingga 335,6 nT. Berdasarkan anomali magnetik dan pola struktur daerah penelitian, diduga adanya Struktur geologi yaitu sesar. Variasi nilai intensitas medan magnet merupakan parameter dalam menentukan nilai suseptibilitas. Nilai suseptibilitas Laut Sulawesi yaitu 0,0656 SI hingga 0,0677 SI. Berdasarkan nilai suseptibilitas, struktur geologi daerah penelitian didominasi batuan jenis andesit, basaltik, dan batuan metamorf.
\end{abstract}

Kata Kunci: Metode Magnetik, Struktur Geologi, Suseptibilitas, Anomali Magnetik

\section{Latar Belakang}

Pulau Sulawesi berada pada pertemuan lempeng Indo-Australia, lempeng Eurasia dan lempeng Pasifik. Lempeng tersebut saling menumbuk sehingga mengakibatkan wilayah pulau Sulawesi dan sekitarnya memiliki kondisi geologi yang sangat kompleks. Dampak dari tumbukan lempeng tektonik ini juga dapat mengakibatkan Pulau Sulawesi menjadi wilayah yang sangat rawan bencana alam kebumian khususnya bencana gempa bumi. Pulau Sulawesi dan sekitarnya, khususnya daerah bagian utara yang letaknya didarat maupun di laut merupakan daerah yang dekat dengan sumber gempa bumi dan penyebab tsunami akibat proses tektonik. Daerah Sulawesi utara terdapat sesar aktif yang menimbulkan munculnya fenomena geologi. Sumber gempa bumi di laut berasal dari penunjaman sublempeng Sulawesi Utara, lempeng Sanghie dan lempeng Panggungan Mayu [6]. Gempa yang terjadi di laut ini akan menimbulkan tsunami. Selain itu, laut ini terdapat sumber daya alam yang disebabkan adanya mineralisasi dari gunung api bawah laut.

Berdasarkan keberadaan mineral serta potensi bencana alam yang mungkin terjadi, maka diperlukan penelitian lebih lanjut terkait struktur geologi bawah permukaan menggunakan salah satu metode geofisika, yaitu metode magnetik. Metode magnetik adalah metode yang memanfaatkan variasi nilai suseptibilitas dan anomali magnetik batuan bawah permukaan untuk mendeteksi jenis batuan atau struktur geologi, patahan atau sesar, intrusi batuan beku, geothermal, mineral logam dan sebagainya [11].

\section{Metodologi}

Kegiatan tim Pusat Penelittian Kelautan (PPPGL) pada tahun 2016 di Laut Sulawesi, dan secara administratif masuk dalam Provinsi Gorontalo dan Sulawesi Utara (Gambar 1).

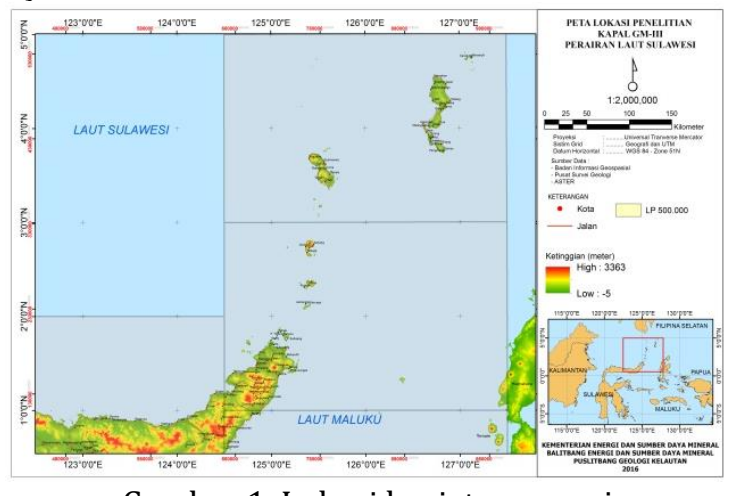

Gambar 1. Lokasi kegiatan survei

Langkah - langkah penelitian yaitu Data yang terukur dilapangan adalah data intensitas medan magnet. Langkah pertama yang dilakukan adalah mengkoreksi data medan magnet total dengan koreksi harian dan koreksi IGRF untuk mendapatkan anomali total. Koreksi IGRF digunakan untuk menghilangkan pengaruh medan magnet dari dalam bumi yang 
disebabkan oleh medan magnet utama. Setelah didapatkan nilai anomali total, dilakukan reduksi ke kutub untuk menghilangkan pengaruh inklinasi dan deklinasi. Anomali hasil reduksi ke kutub dilakukan pemisahan menggunakan filter gaussian regional/residual sehingga didapatkan anomali regional dan anomali lokal. Diagram alir penelitian dapat dilihat pada Gambar 2 .

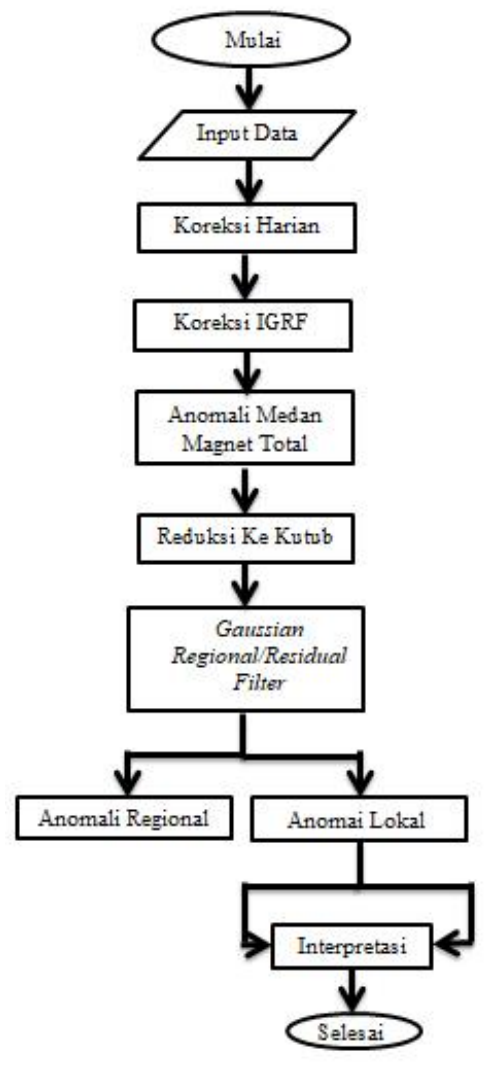

Gambar 2. Diagram Alir Penelitian

Dalam penelitian ini, untuk memperoleh nilai suseptibilitas batuan ditentukan oleh persamaan sebagai berikut:

$\mathrm{I}=\kappa \mathrm{H}$

Dengan $\kappa$ adalah suseptibilitas, I adalah intensitas magnetik dalam nT, dan $\mathrm{H}$ adalah kuat medan magnet bumi dengan nilai $6 \times 10^{4}$ dalam nT.

\section{Hasil dan Pembahasan}

Nilai anomali total merupakan nilai medan magnet yang telah melalui tahapan koreksi variasi harian dan IGRF. Hasil ini masih menonjolkan anomali yang disebabkan oleh sumber yang dangkal dan dalam sehingga akan mempersulit interpretasi. Nilai anomali ini juga belum dilakukan transformasi reduksi ke kutub sehingga masih dipengaruhi oleh inklinasi dan deklinasi.
Berdasarkan anomali total laut Sulawesi yang terlihat pada Gambar 3 didapatkan nilai anomali total berkisar $-138,9$ nT sampai dengan 97,4 nT. Selanjutnya nilai ini diklasifikasi berdasarkan tingkat anomali anomali rendah dan sedang melalui skala warna. Anomali rendah berwarna biru tua hingga hijau agak kekuningan dengan nilai -138,9 nT sampai dengan -5,8 nT. Anomali Sedang kuning hingga ungu dengan nilai 0,7 nT sampai dengan 97,4 nT. Anomali rendah tersebar bagian tenggara dan sebagian tersebar di tengah, barat daya dan timur laut. Anomali sedang tersebar bagian barat laut hingga ke timur laut dan sebagian tersebar di tengah serta tenggara, barat daya hingga ke barat laut, sebagian dibagian tengah dan bagian timur laut.

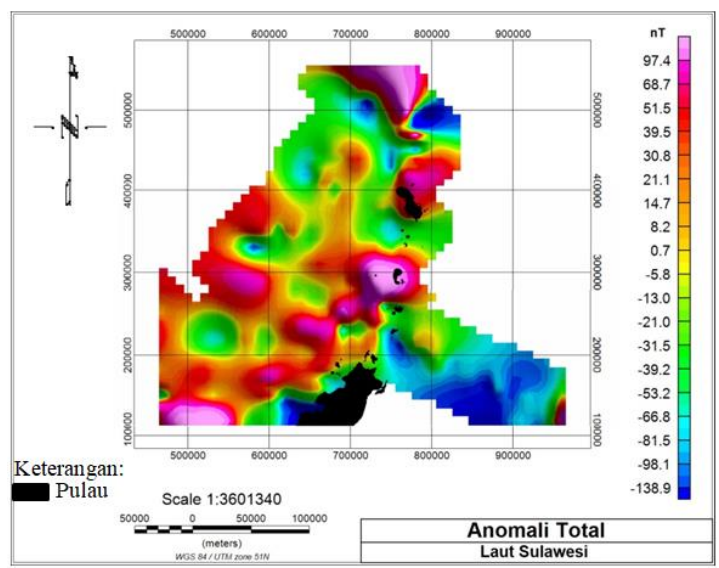

Gambar 3. Anomali Total Laut Sulawesi

Anomali regional laut Sulawesi memiliki nilai berkisar -339,4 nT sampai 190 nT dengan ditandai warna biru muda hingga ungu. Pada Gambar 4, nilai anomali diklasifikasi berdasarkan tingkat anomali sangat rendah, rendah dan sedang melalu skala warna. Anomali sangat rendah ditandai warna biru tua dengan nilai $-339,4$ nT yang tersebar dari selatan hingga barat laut dan bagian timur laut. Anomali rendah ditandai warna biru muda hingga kuning dengan nilai berkisar -294,2 nT sampai -0, nT yang tersebar dari bagian selatan, barat laut, sebagaian berada timur laut dan tenggara. Anomali sedang ditandai warna kuning tua hingga ungu dengan kisaran nilai 31,0 nT sampai 190,4 nT yang tersebar di bagian barat, utaran dan tenggara. 


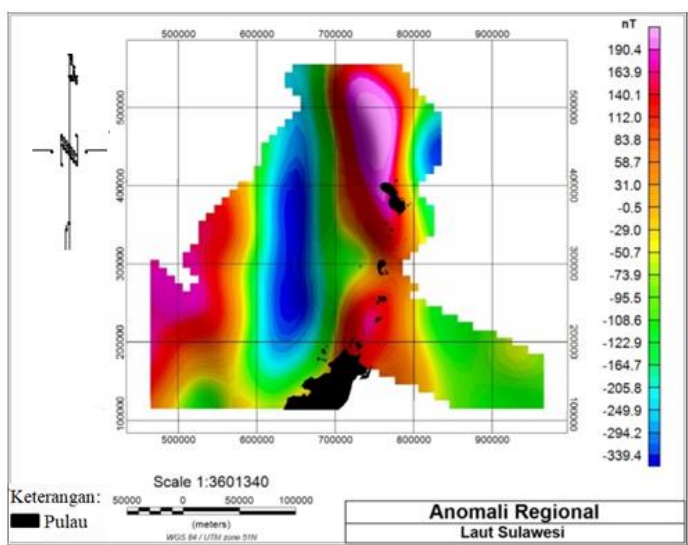

Gambar 4. Anomali Regional Laut Sulawesi

Berdasarkan anomali lokal Gambar 5 diperoleh nilai berkisar -290,0 nT sampai 335,6 nT ditandai dengan warna biru tua hingga ungu. Selajutnya dikelompok menjadi anomali rendah, sedang dan tinggi berdasarkan klasifikasi [7]. Anomali rendah berkisar -290,0 nT sampai -6,3 nT dengan skala warna biru tua hingga hujau yang tersebar utara memanjang hingga ke selatan, sebagian tersebar dari selatan sampai barat laut. Anomali sedang berkisar antara 14,7 nT sampai 180,8 nT dengan skala warna kuning hingga merah yang tersebar sepanjang utara sampai selatan dan barat. Anomali tinggi berkisar 335,6 nT dengan skala warna ungu yang tersebar utara sampai selatan.

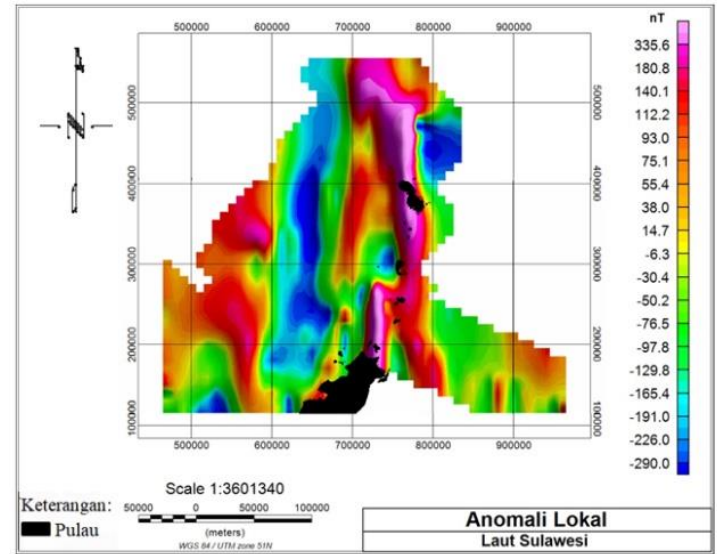

Gambar 5. Anomali Lokal Laut Sulawesi

Pola anomali tinggi rendah yang diserta dengan daerah bersegmen dengan pola redah tinggi pada daerah yang cukup luas mengindikasikan adanya sesar atau patahan [3]. Adanya nilai anomali yang kontras antara positif dan negatif pada peta kontur anomali lokal sehingga adanya pengaruh geologi yang dihasilkan yaitu terdapat patahan atau sesar. Berdasarkan penafsiran pola kelurusan struktur dari peta altimetry batimetri di kawasan Sanghie bahwa daerah penelitian tersebut terdapat patahan [11]. Bidang sesar daerah tersebut dapat terlihat dengan jelas berdasarkan peta anomali lokal yang telah dioverlay dengan pola kelurusan struktur dari peta altinetri batimetri (Gambar 6).

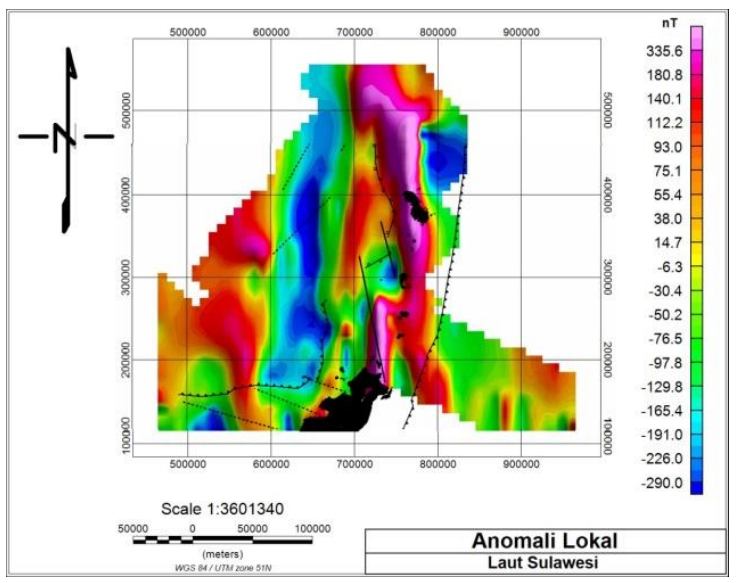

Gambar 6. Anomali Lokal yang dioverlay Dengan Pola Struktur dari peta GMTmap v.3.4.1, 2005 (Permana at al., 2008)

Anomali lokal dioverlay dengan pola struktur menggunakan perangkat lunak (Gambar 6 ). Pola anomali negatif dan positif diperkirakan berhubungan dengan struktur kelurusan yang berarah barat laut sampai tenggara dan pola kelurusan berarah timur lautbarat. Selain itu juga, diduga bagian dari paritan Cotabato pada arah utara sampai selatan. Pola anomali ini juga terdapat adanya patahan yang berarah tenggara sampai barat laut. Anomali yang berwarna biru tua diduga sebagai cekungan.

Dari anomali yang ditimbulkan maka dapat diketahui batuan penyusunnya. Gambar 7 adalah pola sebaran nilai suseptibilitas batuan berdasarkan nilai intensitas magnetiknya.

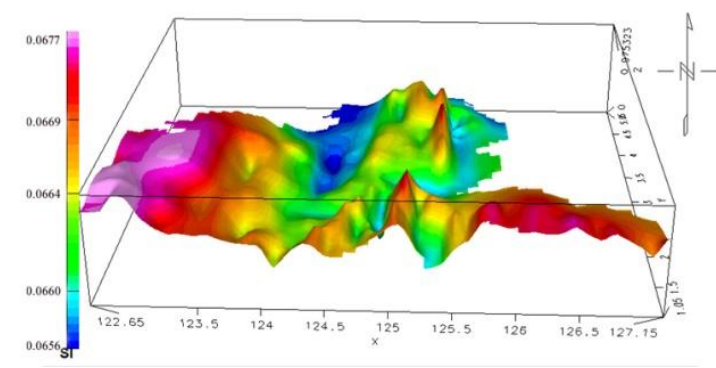

Gambar 7. Nilai Suseptibilitas Medan Magnet Laut Sulawesi

Berdasarkan nilai intensitas magnetik didapatkan pola sebaran suseptibilitas batuan yang ditunjukkan Gambar 7. Pola sebaran yang didapatkan berdasarkan persamaan matematis (1) menjadi perkiraan dalam menentukan jenis batuan dengan anggapan nilai medan magnet 
bumi konstan. Nilai Suseptibilitas berbanding lurus dengan nilai intensitas medan magnet. Nilai intensitas medan magnet tinggi memiliki suseptibilitas yang tinggi juga begitu sebaliknya, Nilai intesitas medan magnet rendah memiliki suseptibilitas rendah.

Berdasarkan klasifikasi Tabel 1 [14], nilai suseptibilitas yang berkisar 0,0656 hingga 0,0677 daerah penelitian diperkirakan sebagai batuan beku andesit dan basaltik serta terdapat juga batuan jenis metamorf. Batuan andesit dan basalt ini mendominasi batuan penyusun di daerah penelitian dikarenakan daerah penelitian merupakan daerah lempeng samudra [5]. Daerah penelitian termasuk bagian mandala barat bagian utara dengan batuan yang bersifat riodasitik sampai andesitik dengan batuan dasar basaltik [12]. Berdasarkan geologi daerah penelitian di dominasi oleh formasi batuan gunungapi yang umumnya bersusunan andesit hingga basalt. Nilai suseptibilitas magnetik batuan 0,067833 sampai 0,065333 SI didominasi oleh batuan beku jenis andesit dan basalt, dan batuan metamorf [5].

\section{Kesimpulan}

Adapun kesimpulan yang didapat adalah sebaran nilai anomali lokal yang diperoleh berkisar -290,0 nT sampai 335,6 nT ditandai dengan warna biru tua hingga ungu. Adapun struktur geologi Laut Sulawesi terdapat sesar. Struktur geologi di Laut Sulawesi memiliki komposisi batuan dengan nilai suseptibilitas 0,0656 hingga 0,0677 SI. Berdasarkan nilai suseptibilitas, Laut Sulawesi didominasi batuan beku jenis andesit dan basaltik, dan batuan metamorf.

\section{Pengakuan}

Penulis mengucapkan terima kasih kepada Pusat Penelitian dan Pengembangan Geologi Kelautan Bandung atas dukungan data dalam penelitian ini.

\section{Daftar Pustaka}

[1] Arief, R. T.; Lili, S.; Haryadi, P. and Eko, T., 2013, Gunungapi Bawah Laut Kawio Barat, Perairan Sanghie, Sulawesi Utara: Aktivitas Hidrotermal dan Mineralisasi, J. Geologi Kelautan.,11:1-8.

[2] Catur, F. S., 2018, Interpretasi Struktur Bawah Permukaan Dan Identifikasi Jalur Sesar Di Kecematan Bagelen Kabupaten PurworejoDenganMetode Geomagnet, Universitas Negeri Yogyakarta, Fakultas Matematika Dan Ilmu Pengetahuan Alam, Yogyakarta, (Skripsi).
[3] Fashihullisan, A.L.; A. Susilo and A.F. Jam'an, 2014, Identifikasi Sesar Dan Intrusi Berdasarkan Perbandingan Antara Filter (RTP,Upward, Downward, dan analitic Signal) Data Mapping Regional Magnetik Daerah Garut Jawa Barat, J. Physic Student., 2:1-7.

[4] Heryanto, S.T.; Ardi, N.D. and Ilahude, D., 2015, Identifikasi Struktur Geologi Bawah Permukaan Dasar Laut Berdasarkan Interpretasi Data Anomali Magnetik Di Perairan Teluk Tolo Sulawesi, J. Fibusi (JoF).,3:1-7.

[5] Intan, D. P.; Dadi, R.; Catur, P. and Nanang, D.A., 2018, Identifikasi Struktur Geologi Bawah Permukaan Berdasarkan Nilai Suseptibilitas Magnetik Batuan Di Laut Sulawesi, J. Meteorologi Klimatologi dan Geofisika., 5:1-7.

[6] Lira, N., 2017, Analisis Parameter Seismik Gempabumi Wilayah Lengan Timur Sulawesi dengan Metode Empiris, Universitas Islam Negeri Alauddin, Fakultas Sains dan Teknologi, Makassar, (Skripsi).

[7] Mochamad; Suparman and Munandar, A., 2011, Survei Aliran Panas Daerah Panas bumi Massepe, Kabupaten Sidrap, Provinsi Sulawesi Selatan, Kajian Panas Bumi, Kelompok Program Penyelidikan Panas Bumi Sulawesi Selatan, Pusat Sumber Daya Geologi.

[8] Nhirwana, B. and Subarsyah, 2009, Pemodelan 3-D Suseptibilitas Magnetik Bawah Permukaan Dasar Laut Perairan Langsa Selat Malaka Sumatera Utara, Pusat Penelitian dan Pengembangan Geologi Kelautan, Bandung.

[9] Nugraha, T.; Catur, P. and Mimin, I., 2015, Analisis Model Data Anomali Magnetik Untuk Mengidentifikasi Struktur Geologi Dasar Laut Perairan Flores, J. Fibusi (JoF)., 3: 1-12.

[10] Pasau, G.; Ferdy; Gerald, H. T., 2017, Pengamatan Seismisitas Gempa Bumi Di Wilayah Pulau Sulawesi Menggunakan Perubaahan a-b, J. Mipa UNSRAT Online., 6:31-35.

[11] Permana, H.; McConanchy, T.; Priadi, B.; Parr, J.; Hananto, N. D.; Burhanuddin, S.; Pirlo, M.; Brodjonegoro, I. S. and Sultan, 2008, Gunungapi Dan Kegiatan Hidrotermal Bawah Laut Di Perairan Sulawesi Utara Mineralisasi Dan Implikasi Tektonik, J. Geologi Kelautan., 6:69-70. 
[12] Rachmat, B. and Delyuzar, I., 2011, Pola Anomali Magnet dan Nilai Suseptibilitas Dari Batuan Dasar Pada Pemetaan Geologi Dan Geofisika di Perairan Teluk Bone Sulawesi Selatan, J. Geologi Kelautan.,9:1322.

[13] Sehah, Sukmaji, A.R. and Chandra, A.P., 2015, Interpretasi Model Anomali Magnetik Bawah Permukaan Di Area Pertambangan Emas Rakyat Desa Cihonje, Kecematan Gumelar, Kabupaten Banyumas, J. Bekala Fisika., 18:51-58.

[14] Telford, W.M., 1990, Applied Geophysics Second Edition, Cambridge University Press, London. 